This is an author-generated postprint (a postprint is a draft of an article after it has been peer reviewed, but before the publisher's typesetting and copy editing).

This article appears in Public Library Quarterly. The publisher's version of this article is available at the following DOI:

https://doi.org/10.1080/01616846.2019.1637222

This work is licensed Creative Commons Attribution 4.0, CC BY (https://creativecommons.org/licenses/by/4.0/).

\title{
Service Blueprinting: A Method for Assessing Library Technologies within an Interconnected Service Ecosystem
}

\begin{abstract}
Service blueprinting is a method for designing, assessing, and improving services. This article provides a practical overview of the service blueprinting process for library technology services. We begin by outlining the recent conversation around library technologies, service design, and service blueprinting. We then detail an iterative case study for the creation process of a service blueprint, followed by a discussion of the service insights and improvements that resulted from this activity. We conclude by offering a set of recommendations for creating and analyzing service blueprints. Ultimately, the service blueprint is a useful tool for understanding the operation of a service, and for situating that service within a broader and interconnected library ecosystem.
\end{abstract}

Service design; service blueprinting; library technology; service ecosystem

\section{Authors}

Scott W. H. Young http://orcid.org/0000-0002-3082-4057.

Sara Mannheimer http://orcid.org/0000-0002-1433-6782.

Doralyn Rossmann http://orcid.org/0000-0002-6490-4223.

David Swedman http://orcid.org/0000-0001-5241-2582.

Justin D. Shanks http://orcid.org/0000-0002-0587-8256. 


\section{Introduction}

Service blueprinting is a method for designing, assessing, and improving services. As a method of service design, blueprinting is concerned with empathy, user-centeredness, and the broader service ecosystem. Service blueprinting is particularly effective at illuminating the complexities of new library technology services, which are often accompanied by new sets of challenges for both library users and library staff. We applied service blueprinting to a new visualization display wall in our library, iterating three different blueprint versions over two years. This process allowed us to better understand and assess the display wall service within the context of a complex, interconnected ecosystem of library service and staffing. We identified several ideas for improvements of the display wall. We also identified several approaches for successfully creating and implementing a service blueprint.

\section{Background and Context}

\section{Service Blueprinting and Service Design}

Service blueprinting is a method for understanding how a new or existing service integrates into the complexity of an interconnected library service ecosystem. A service blueprint provides a visual flow of a service operation. The function of a service blueprint is to assess the operation and delivery of a service, and to generate new ideas for improving the service. The scope of a blueprint typically includes three main service areas: user-facing interactions, behind-the-scenes staff actions, and the technology systems that support the service. The technique of service blueprinting was developed through the tradition of service design (Shostack 1984; Marquez and Downey 2015a). Within libraries, service design generally and service blueprinting particularly is recognized as a useful practice for planning, assessing, and improving technology services. When implementing a new collaborative library space, for example, Deitering and Filar-Williams (2018) note, "The most useful tool in our planning stages was blueprinting." In terms of scope, a service can be understood generally to include any interaction that a user undertakes to access information or fulfill a task. In essence, everything within a library has the potential to operate in service to user goals (Marquez and Downey 2016, 14-17) , and therefore the blueprint is an adaptable, useful tool for a full range of library services.

In practice, the service blueprint typically takes the form of a templated schematic. In the blueprint representation, different component parts of the service operation are shown vertically, and forward progress through time is shown horizontally. Figure 1 shows a blank template for a service blueprint, with five component parts of the service along with the line of visibility: 

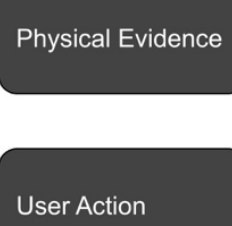

Figure 1. Blank Service Blueprint template

- physical evidence identifies the people and things with which the user interacts

- user actions identify the actions taken by the user during the course of the service

- front-line staff actions identify the interactions that occur between users and the public services staff

- behind-the-scenes staff actions identify the work and coordination of any staff that does not directly involve user interactions

- support infrastructure and systems identifies the technology and space that supports the service

- the line of visibility delineates the service components that are visible to the user from the components that occur away from the user's line of sight.

To complete this blueprint, the workflow of a service is visually represented through time according to the service components of the blueprint. The blueprint then shows the different parts of a service at various stages, revealing holistically the relationships among various spaces, staff, and technologies that comprise the service. The blueprint is completed collaboratively by the library staff who support the service. Importantly, library users are not typically consulted in the creation of a service blueprint. In this way, the 
blueprint represents a conceptual model of a service as it appears to the service providers. The internal focus of the service blueprint makes it an especially useful tool for highlighting internal relationships among staff and technology systems, and for generating dialogue among diverse stakeholders towards service improvement insights.

\section{Technology Services in Libraries}

Service blueprinting is particularly useful in navigating the complexities of the provision of technology services in libraries. Information literacy now goes hand in hand with digital literacy. With the advent of personal computers and the web, information is easily accessed through search engines and databases, then processed and explored using computer software. In an effort to keep up to date with patrons' information seeking needs, libraries increasingly focus on innovation (Youngman 1999; Weiner 2003). Consequently, early adoption of and support for new technology services have become key to libraries' missions. The New Media Consortium periodically publishes the Horizon Report: Library Edition, a publication that forecasts near-term trends and technology developments in libraries, outlines related challenges, and suggests ideas for solutions (Adams Becker et al. 2017). The Library Information Technology Association (LITA) Guide series focuses on technology implementation and management in libraries (see, for example, Block 2017; Silveira 2018; Ippoliti 2018; Kirsch 2018). Publications like these showcase the value placed by libraries on staying up to date with new technologies and technology trends.

Such new technologies are often offered as services in library public spaces. Public computing, self-checkout machines, digital signage, and technology equipment checkout (e.g. iPads, laptops, audio/video equipment) are ubiquitous (Clark and Palmer 2005; Bertot 2009). Some libraries also support more specialized services such as makerspaces (sometimes called hack labs) with computers, 3D printers, and audio/video capture and editing tools (Moorefield-Lang 2015; Meyer and Fourie 2015; Willett 2016); large display walls for data visualization, data analysis, presentations, events, and teaching (Brosz, Rashleigh, and Boyer 2015); and augmented or virtual reality equipment (van Arnhem, Elliott, and Rose 2018).

Accompanying these new technology services are a new set of challenges for both library users and library employees. First, there are implications for user privacy. Networked technologies such as cloud-based services and library websites may track users or otherwise collect user data (Kritikos and Zimmer 2017; O'Brien et al. 2018) and physical technologies such as RFID technology, laptops, scanners, and self-checkout machines pose challenges regarding data and network security, workstation security, and intellectual property (Nichols Hess, LaPorte-Fiori, and Engwall 2015; Ferguson, Thornley, and Gibb 2015). During 2015-2016, the Intellectual Freedom Committee of the American Library 
Association (ALA) produced guidelines documents (ALA 2016b) and privacy checklists (ALA 2016a) to support patron privacy in libraries, including in the areas of E-book Lending and Digital Content Vendors; Data Exchange Between Networked Devices and Services; Public Access Computers and Networks; Library Websites, OPACs, and Discovery Services; and Library Management Systems. These guidelines and checklists provide actionable advice to libraries implementing new technologies, covering topics such as privacy policies, access control, and data collection.

Second, new technologies in the library require specialized training for both users and library employees. In order for a new technology service to be successful, both library employees and library users need to understand the purpose and benefit of the technology, and they must know how to use the service (Deissler et al. 2015; Moorefield-Lang 2015; Brown et al. 2017). In addition to training, new policies and rules must be implemented and communicated to patrons.

Lastly, new technologies don't exist in a vacuum-they must be integrated into a complex ecosystem of existing library services (Marquez and Downey 2015a; Marquez, Downey, and Clement 2015, 141). Service blueprinting can be used when implementing new technology services to highlight the broader context of interconnected services, and to investigate how new services complement or contrast with existing ones. In the case study section below, we complete a service blueprint, demonstrating and discussing its usefulness for library technology.

\section{Service Blueprinting in Practice}

\section{Creating and Iterating a Blueprint}

We applied the service blueprinting technique to a newly-implemented display wall in our library space. The display wall service and the immediate space it occupies can take on various configurations. At times, the display wall can be configured for activities such as group presentations (Figure 2); at other times, it can in a more dormant state, with casual seating (Figure 3). 


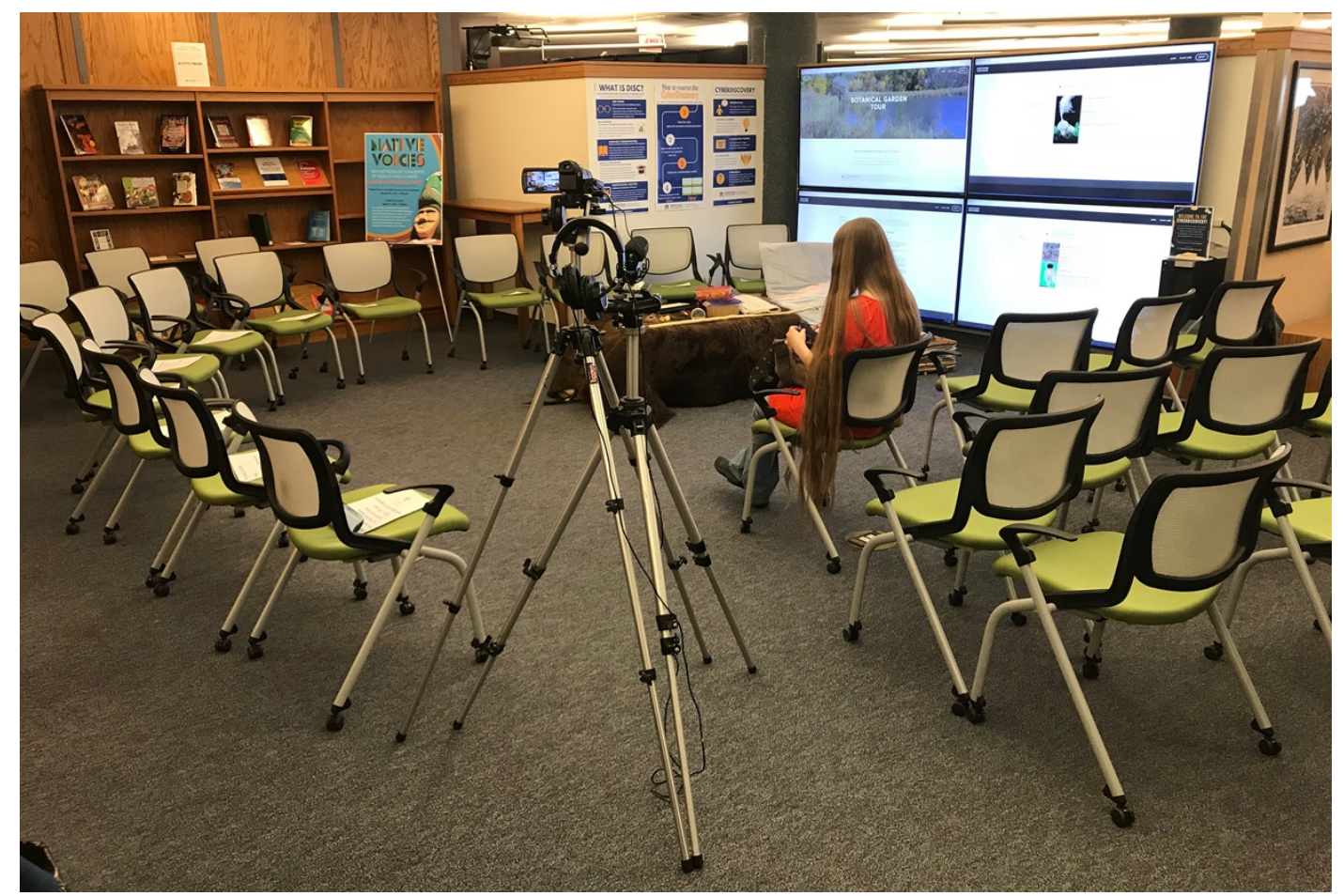

Figure 2. The Library's display wall, with display wall activated and furniture arranged for a presentation.

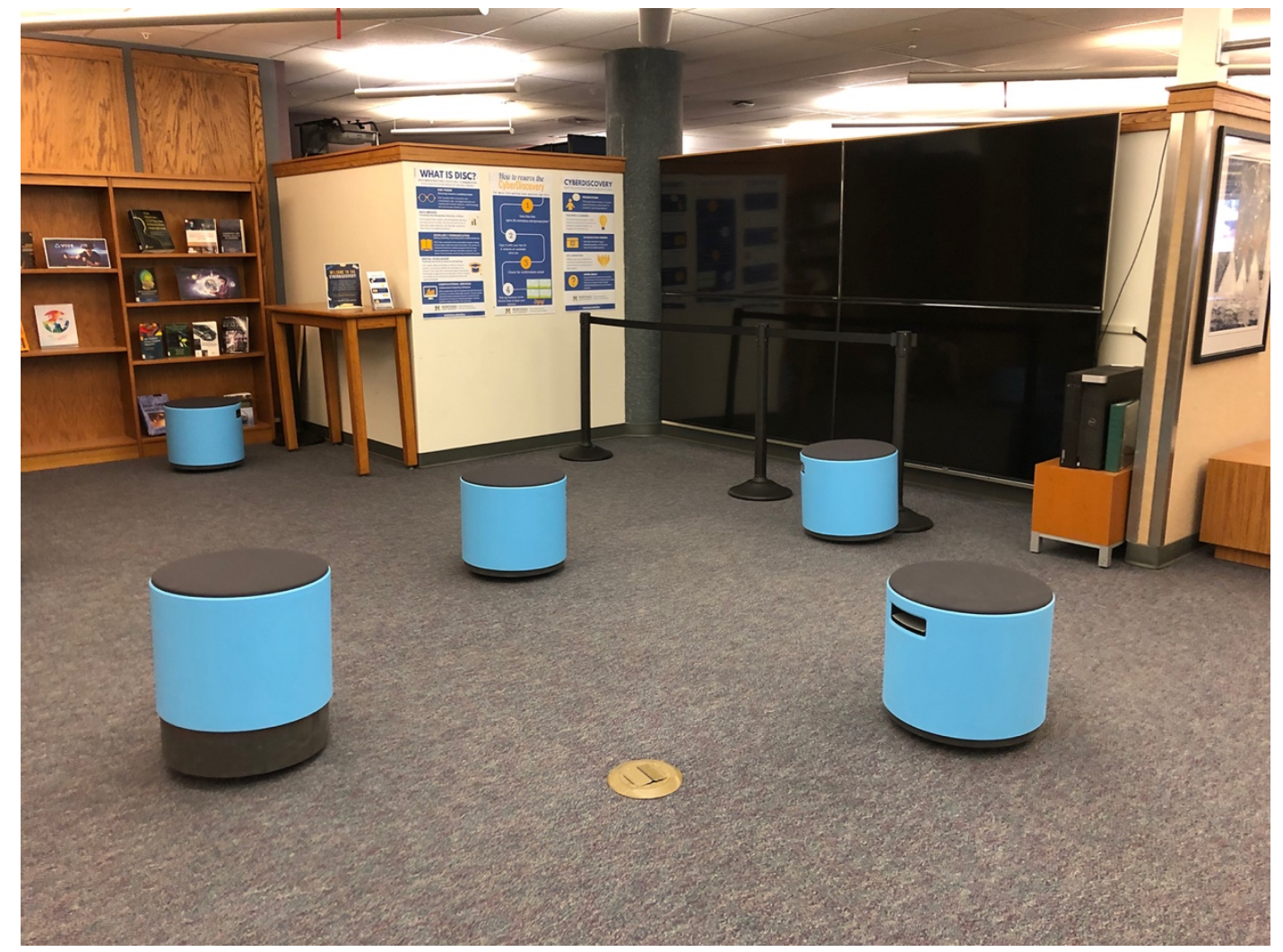

Figure 3. The Library's display wall, with display wall unactivated and furniture arranged for casual seating and stanchion to protect screen from damage. 
Our display wall was installed in a high-traffic area on the first floor of the library, so as to easily showcase its presence and connect the service to our user community. The display wall was purchased with student-oriented technology funds in partnership with our university information technology (IT). The display wall provided an opportunity to introduce advanced technology to our user communities. At the same time, the new display wall introduced a broad set of questions related to its operation and integration with other existing services and staffing models: Who is primarily responsible for this new service? Who should staff the display wall? Will users know how to interact with the display wall? How should the furniture be arranged? What kind of signage should be present? What new technology systems needs to be maintained so that the display wall can function properly? How do different library departments-public services, technology staff, administrationinterrelate in delivering the service to users?

We identified the service blueprint as a useful tool for answering these and other questions relating to the operation of the display wall service. To date, we have created three versions of a service blueprint for our display wall. Each version was created at a different point in time throughout the life of the service. This iterative approach has allowed us to review and analyze changes to the service over time, which helps ensure that the service operates properly in response to continual changes in technology, staffing, space, and other related services. The sections below discuss the three versions of our service blueprint.

\section{Blueprint: Version 1}

To create our first blueprint, a group of 15 library staff conducted a design workshop on service blueprinting in April 2017. As is typical for creating a service blueprinting, no endusers participated in the workshop. The workshop was facilitated by members of the library staff who have a background in service design, using descriptions available from the Learning Space Toolkit website serving as an introduction to the tool. ${ }^{1}$ Participants worked in small groups of 4-6 to design a blueprint. To complete the blueprint, participants documented five operational service segments of the display wall: physical evidence, user actions, front-line staff actions, behind-the-scenes staff actions, and support infrastructure and systems. The structure of the service blueprint guided participant discussions and contributions. Discreet components of the service were documented on sticky notes and added to a poster-sized service blueprint template (Figure 4).

\footnotetext{
${ }^{1}$ Learning Spaces Toolkit, a resources for designing and sustaining technology-rich informal learning spaces. https://learningspacetoolkit.org/services-and-support/service-blueprint/
} 


\section{Service blueprint}
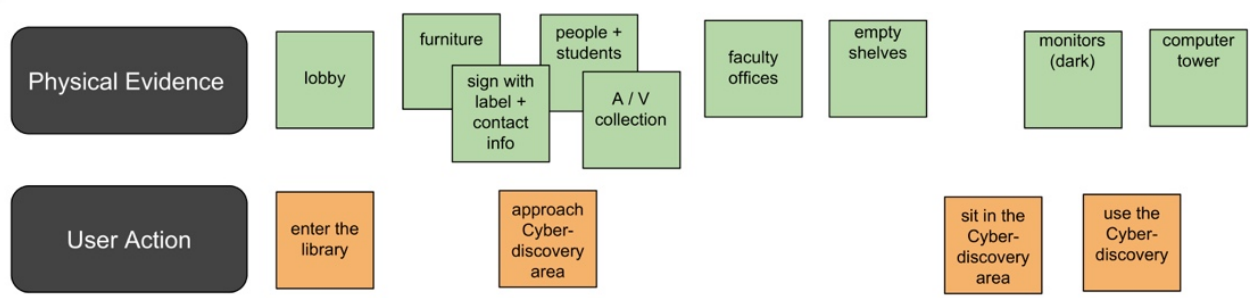

area

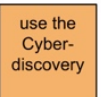

request

help

\section{Front-line Staff} Action

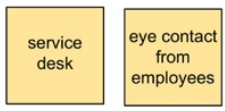

from
employees

faculty in

nearby

offices

Line of Visibility

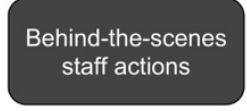

Support

infrastructure and

systems
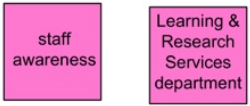

department
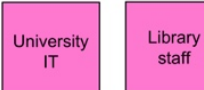

DISC subgroup

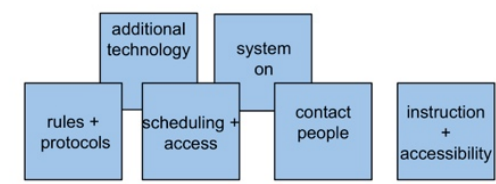

Figure 4. Service blueprint, Version 1. Library staff completed the blueprint according to the five operational components of the service: physical evidence, user action, front-line staff action, behind-the-scenes staff actions, and support infrastructure and systems.

This display wall blueprint represents a conceptual model of the service operation, showing the sequence of steps taken by a user in locating and using the service. As we conceptualize the user interacting with the service, each step is sequentially recorded according to the five key service segments. For example, the workshop participants noted that the first user action is to "enter the library." Concurrently with this user action, the group identified that the front-line staff action would be centered around our main service point, the "service desk," and that the physical evidence at this point would be the library's "lobby." At the same time, the behind-the-scenes staff actions would be a "staff awareness" of the user. Workshop participants completed the blueprint by identifying each component part of the operation of the display wall as the user and the service flow forward through time.

This version of the blueprint represents the then-current operation of the service. By providing a visual map of the service, the blueprint allowed us to identify specific points of improvement for the service. Version 2, which will be described in the following section, 
represents an updated blueprint that includes new insights and improvements in the operation of the service.

\section{Blueprint: Version 2}

To create the second version of the blueprint, we presented our version 1 blueprint to a stakeholder group consisting of university information technology (IT) and library staff who support the display wall. In a meeting scheduled a few weeks following our first blueprinting workshop, we discussed the insights that emerged from the first blueprint, and added new ideas on top of the first blueprint using new sticky notes. Figure 5 shows a representation of our second blueprint; notes outlined in bold show new ideas for service improvements that came forward during our version 2 session. Ideas for improvements included new instructions for using the display wall, a troubleshooting guide, a reservation application, identifying a key contact person, activating eye-catching screensavers, and connecting users with a help ticketing system.

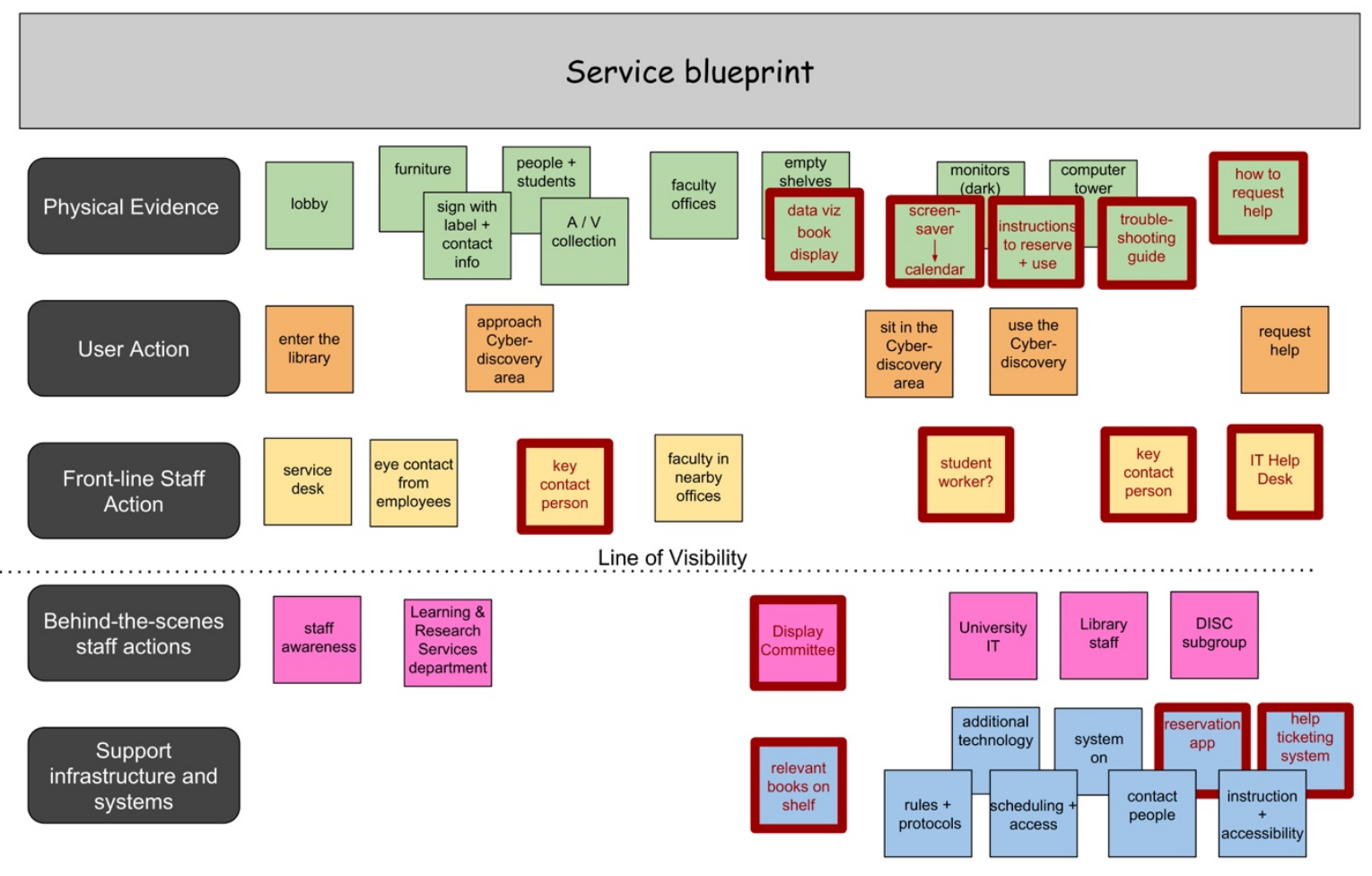

Figure 5. Service blueprint, Version 2. Sticky notes outlined in bold represent ideas for service improvement 
As an example of our process, the group recognized through our blueprint discussions that the physical evidence a user encounters when approaching the service is "empty bookshelves" that are adjacent to the display wall. This part of the service design was overlooked in our initial implementation of the service. In response, the group developed the idea to create a "data viz book display" as a new element of physical evidence for users to see and engage with. To help put this idea into practice, we would coordinate with our library's "display committee" as a behind-the-scenes staff action, which would result in new support infrastructure in the form of "relevant books on shelf." The second version of our blueprint allowed our stakeholder group to see and talk through the operational flow of the new display wall service. This dialogue highlighted the strengths of the service-and also the pain points for users and support staff. Following our second version, many of the blueprint insights were put into practice to improve our display wall service. We provide an in-depth discussion of our first two service blueprints in a previous article [reference blinded for review]. We expand on our service blueprinting process below, demonstrating the usefulness of the blueprint as an iterative tool for designing services over time.

\section{Blueprint: Version 3}

Two years after the creation of the second blueprint, we recognized that the display wall technology had changed and its service operation has evolved. For example, the library has recently acquired a virtual reality headset that can be used with the display wall-but how does this new technology service interact with our existing display wall technology, and what is the necessary staffing model to support the service? In fact, staff turnover and training has been an ongoing challenge for the display wall, and we looked to a refreshed blueprint as a way to provide an up-to-date, holistic view of staffing needs across departments. In the time since we first launched the display wall, we have also introduced new types of presentations and workshops based on the technology, including a speaker series, an art history exhibition and relaxation and de-stress programming. These new functions are a part of the evolving display wall service, yet it's not fully clear how best to bring these functions together coherently. Also unresolved is the question of furniture, including the right mixture of tables, chairs, and movable walls that provide semi-enclosed space while using the display wall. Finally, library staff have taken over more management of the system, moving away from reliance on a specialized user interface originally proposed by university IT, onto a more widely understood typical Windows interface. In the face of these changes and challenges, we turned back to blueprinting to help illuminate the service operation.

In January 2019, we organized a new workshop with display wall stakeholders from across the library and university IT with the goal of creating a third blueprint that captures the current operation of the service. Similar to the workshop that led to the creation of our first 
blueprint, this workshop was facilitated by a library staff member with knowledge and experience with the service design mindset and methodology (Marquez and Downey 2015b). The workshop was attended by 12 staff members, who were organized into three small groups of 4 participants each. At the conclusion of the 75-minute workshop, participants had co-created three different versions of the blueprint. The small-group structure proved valuable, in that it allowed for different ideas to come forward from different parts of the organization, thereby demonstrating different viewpoints and knowledge gaps of various staff. Figure 6 shows one of our version 3 blueprints.

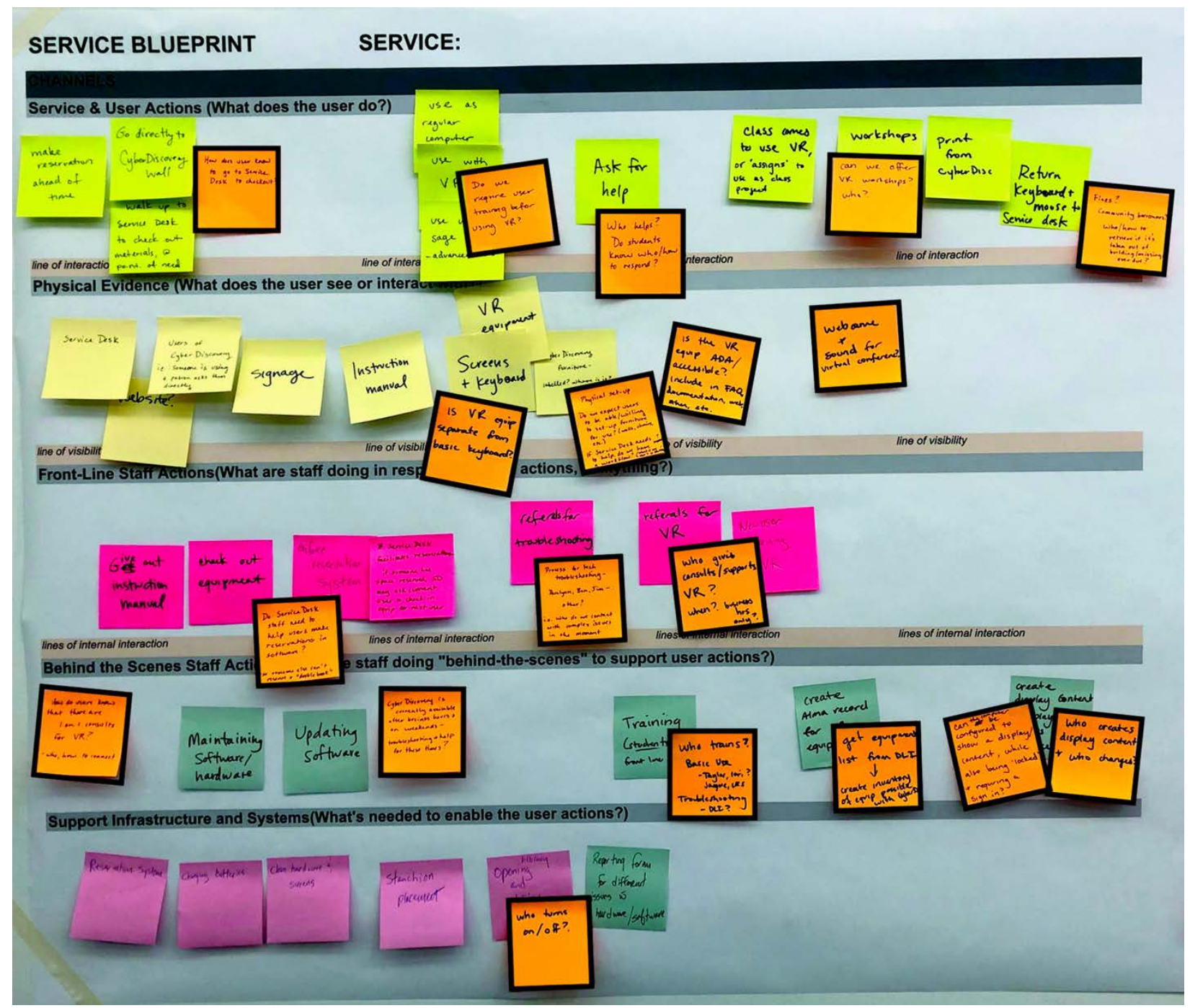

Figure 6. Version 3 Service Blueprint, with color coding across different service segments. In this version, orange notes (outlined in bold) indicate questions or ideas for improvements. 
In this third round, we also introduced a two subtle but meaningful revisions to the service blueprinting process. First, we reordered the first two service components so that "user action" appeared above "physical evidence," thus presenting the blueprint in a more logical order-first accounting for the user action and then recording the physical layout of the space. Next, in addition to employing a different color of note to complete each service component (as we had for the first two versions) we also asked participants to record questions and new ideas for improvements using a unique color of note. Figure 6 shows these notes in orange (outlined in bold). Using a unique color for questions and new ideas aided our in-workshop discussion and post-workshop analysis.

Following the completion of the workshop, the facilitator collaborated with a sub-group of display wall stakeholders to analyze and synthesize the blueprints produced by the three small groups. We discuss below the results of this analysis and the service impact of our third round of blueprinting.

\section{Service Blueprinting: Results and Impact}

In our third round of blueprinting, participants in the blueprinting workshop presented a variety of perspectives. The sections below outline the major themes that emerged from these conversations, how these ideas inform operations, how service blueprinting brings together different perspectives for shared awareness and understanding, and how service blueprinting continues to be a useful tool as services evolve.

\section{Themes and needs}

Themes that arose from the third service blueprinting exercise were largely expected as these were similar themes from previous service blueprinting exercises. But, since our previous service blueprinting, we added virtual reality equipment and software to our setup. Also, because we are not requiring users to go through the Sage interface to use the system, instead relying on a Windows desktop as the default interface, the user manual and training are not reflective of current practices. These two changes highlight areas of concern and need to be addressed with the display wall and its use. The needs are italicized with a need tag to indicate that categorization.

The following provides a comprehensive list of the needs which arose for each service segment, derived from the blueprints created during our version three workshop.

Service and User Actions:

- Reserve the system

- Walk up to desk to use without a prior reservation 
- Checkout equipment

- Navigate the interface

- Give referrals to others to use display wall

- Read posters/handouts

- Use as just a regular computer

- Use virtual reality

- Read instruction manual

- Pay fines if return of equipment is late

Physical Evidence:

- Big black screens when system is not active

- Exciting images, such as nature, when system is active

- Other people using the system

- Service desk

- Materials for checkout (keyboard, virtual reality equipment)

- Chairs

- Reservation software

- Website

- Instruction manual

- Need: Updated instructions

- Need: Clear way to know if it's available and how to reserve

- Need: More privacy - perhaps movable walls for a little less out-in-the open feeling

- Need: More on-screen content when system isn't being used

- Need: As much to be automated as possible for system use

- Need: New, better signage and handouts

- Need: To have users sign tech agreement to check out materials

- Need: To address American Disabilities Act compliance or non-compliance in documentation

- Need: Webcam and sound for virtual conferencing

Front-Line Staff Actions:

- Assist with orientation and troubleshooting

- Check out equipment to users

- Answer questions about use

- Checking reservations

- Train student assistants on use of system

- Ask people using system to finish if someone with a reservation needs to use it

- Referrals for troubleshooting 
- Referrals for virtual reality

- Need: Training for virtual reality use

- Need: Training on use of equipment

Behind-the-Scenes Staff Actions:

- Desktop software maintenance

- Workstation backups

- Getting PowerPoint presentations to display properly for library events

- Sage updating and server maintenance

- Updating instruction manual

- Training staff

- Charge virtual reality equipment batteries between uses

- Store equipment behind the library service desk

- Need: Make a list of all virtual reality programs and post in manual and on website

- Need: virtual reality content curation and collection policy

- Need: Create record in the library management system for equipment

- Need: Inventory list from the library technology department with prices for replacement

- Need: To clarify who could/should create display content

Support Infrastructure and Systems:

- Physical computer

- User authorization/access

- Sage stack, auto-load, server

- Technical documentation of Sage

- User manual

- Regular battery charging

- Reservation system

- Place stanchions for screen protection

- Need: Decide and designate who turns system on/off

- Need: Place to report problems

- Need: Maintenance: Clean keyboards and virtual reality equipment and screens

- Need: Training opportunities for users 
New Service Operations and Improvements for the Display Wall

Following the service blueprinting exercise, the data were analyzed for themes and ideas, as outlined in the previous section. From there, needs and suggestions were addressed where immediately possible and other ideas remain on the table for future consideration.

Staff Training and Cross-training

With all of the changes to the display wall since the last service blueprinting exercise and with staff turnover, staff training and cross-training presented itself as an obvious need. Library administration staff were most familiar with the basics of getting the system up and running and library technology staff were most familiar with troubleshooting problems and with using the virtual reality software and hardware. These groups teamed together to do cross training with service desk staff who have to manage checkout of materials and help users with basic questions. While the system is intended to be selfguided using instructions in the user manual, library technology staff are available to assist users with more complex needs if they make an appointment.

\section{Updated User Manual and Scheduling Software}

The user manual created from the previous service blueprinting exercise was already outdated with an emphasis on using the Sage software and no mention of using the system as a typical Windows interface. Also, there were no instructions on how to use the virtual reality software. Library administration staff who regularly use the system for slideshows and other displays updated the instructions on using the system, how to make one application appear across all four screens, and other basic uses and library technology staff added a virtual reality section to the manual. The manual was tested for clarity and comprehensiveness during staff training. We also implemented scheduling software for the display wall area. Users can reserve the display wall for two-hours (renewable once), and related equipment (such as keyboard, mouse, and virtual reality headset) can be checked out from the service desk for the same time period.

Virtual Reality

In addition to the training and updated manual for using the display wall for virtual reality, there were other logistics address for that system. The various pieces for virtual reality that users check out from the service desk were processed by staff to include labeling, barcoding, and a formal location where virtual reality batteries can be recharged. These items were added to our integrated library system and a replacement cost list was created to charge users in case of loss or lack of return. Service desk staff clean and disinfect the virtual reality hardware each time it is returned, as they do with all of our circulating technologies. A web page with a list of all virtual reality software was added to the display 
wall web page along with a usage policy. One remaining goal is to set a collection development policy for the virtual reality software and to decide who is in charge of content curation. Currently, library technology staff manage the software purchase and installation, but it's unclear if this arrangement makes sense in the long term.

\section{Software Complexity and Staffing Model}

One participant from university IT is familiar with the Sage software ${ }^{2}$ originally proposed as the main interface for the display wall and which is used on similar setups at other libraries. The Sage software allows for desktop sharing and video conferencing capabilities with large data sets and visualizations. As a highly-configurable and highly-specialized technology, however, it can be difficult for users to operate and staff to troubleshoot. The participant from university IT sees a lot of potential for this software, while others were disinclined to use it because of its steep learning curve and frequent troubleshooting requirements. As a result, the participant from university IT's group was the only one to bring up ideas around how to manage the use of Sage. While Sage can be used by those few people familiar with the system, it is not a technology that the library has the expertise or bandwidth to promote and support. Our experience demonstrated to us that a display wall service needn't be operated with a specialized software such as Sage. On the one hand, the display wall could be operated with high-performance software, but such software is then dependant on highly-trained and readily-available staff to operate and troubleshoot. On the other hand, our display wall could also be operated with a more accessible and easilysupported software such as Windows, which then provides more direct and regular access to the display wall for a greater number of staff and users with little to no user instruction needed.

Evolving Stewardship of the Technology

Initially, the display wall was maintained by university IT. All but one staff from university IT have been pulled into other projects responsibilities and ownership of the system has been largely assumed by library employees. The shift away from using the Sage software to relying on a typical public Windows setup has made it easier to explore the system and maintain it. Library technology staff have been the primary caretakers of the system, but library administration office staff have taken on the space as a place to do slideshows and displays about library events. Instruction librarians have found the space useful for doing technology-focused workshops such as use of specialized software and resources (e.g. EndNote, R, library databases). As a result of these new various uses and technologies, ownership has evolved into a group model where different departments manage different aspects of the system (signage, software/hardware updates, circulation policies, etc.). The version 3 blueprint exercise highlighted the changes since versions 1 and 2 , and allowed

${ }^{2}$ SAGE2: Scalable Amplified Group Environment. http://sage2.sagecommons.org 
the group to share ideas about their respective areas of "ownership." As seen in the most recent service blueprinting exercise, there is a desire among many library employees to have the system always turned on and displaying content when the system is not in use, in order to make the system more visible and useful. No person or department has been tasked or has taken responsibility for this idea and it seems currently untenable to add to a daily routines for any individual or group.

\section{Physical Spaces}

In the time between the creation of the second and third version of our display wall blueprint, we introduced adjustable height stools to the physical space around the display wall (as seen in Figure 3) and colorful chairs were purchased for the display wall area and placed in front of the display. With space at a premium at the library, we found that these chairs and stools tended to get moved to other spaces on the library's first floor and that tables would get moved in front of the display wall. Also, when it was not turned on, students would prop items like backpacks against the display wall. Unfortunately, one of the colorful chairs ended up too close to the display wall, falling, and breaking one of the screens. While that model was no longer manufactured, we installed a new monitor which was a same-size model from the same manufacturer. Fortunately, we were able to adjust the lighting and contrast to resemble the other three monitors. To protect the monitors, we bought stanchions to place in front of the display wall when not in use. Also, we put away the colorful chairs and only bring them out for events with large numbers of participants. The adjustable stools remain available for everyday use of the display wall. Library administration staff updated the signage by the display wall to explain where to reserve the system and check out the related equipment. A whiteboard was added to allow people to make notations next to the display wall as we noticed mobile whiteboards being moved by students into that area. Another idea that is being explored that was raised through service blueprinting is to add movable walls with glass panels at the top. This arrangement would signal that the space is designated for the display wall, and would give users of the virtual reality software more privacy, while still allowing other users to see that the display wall is available as a service.

\section{Discussion and Recommendations for Creating Service Blueprints}

Over the course of three rounds of blueprinting, our group learned several lessons for successfully facilitating and applying a blueprint, which we discuss below.

\section{Application of the Blueprint for New Technology Services}

Blueprinting is appropriate for any library service. And for technology services specifically, a blueprint can be especially valuable in light of the complexity and novelty of today's 
technologies. In our case, a new visualization display wall was in fact quite complex, drawing together staff and systems not only from multiple library departments, but also from university IT. In terms of novelty, the display wall discussed in this article was our first such technology, and we've since introduced additional new technologies like virtual reality hardware and software that works in conjunction with the display wall. The blueprint proved to be a valuable tool for revealing the interconnectedness of our various staff, systems, and services around this new and challenging technology service. Our blueprinting process produced new improvements that have led to a more coherent and effective operation of our display wall service, ultimately enhancing staff and user experiences of the display wall.

\section{Facilitation of the Process}

Facilitating the process of creating a blueprint will help ensure a useful and usable product. The first step is to assemble representatives from the different stakeholder groups that support the service in question. A blueprint certainly could be created by a single author, but in our experience, a collaborative, cross-departmental co-authorship leads to valuable insights for the service and connections among the service providers. In preparing for our service blueprinting workshop, we adapted an established template from the Learning Space Toolkit. ${ }^{3}$ We then printed blank blueprint templates on a large-scale printer, so that the blueprint template could be attached to a wall. This allows for workshop participants to easily move around to place their own notes and to view the notes of others. We found that small groups of three or four led to effective idea generation and knowledge exchange among all participants. To begin our workshop, we framed the activity by providing a brief overview of service design and service blueprinting, and we were intentional in telling participants how their efforts would translate into improved an improved service for themselves and our users.

\section{Service Blueprinting as a Dialoging Device Among Stakeholders}

Service blueprinting is helpful in situating a service within the broader and interconnected service ecosystem. In addition, the act of co-creating a service blueprint with diverse staff can showcase the interconnectedness of the people who support library services. In this way, service blueprinting can surface common questions and provide a shared point of reference for conversation and dialogue. Practically and concretely, blueprinting raises the "need to know" questions and answers for staff on each department. This process demonstrates where effort and resources are duplicated, and in which direction resources need to be reallocated in order to ensure the proper operation of the service. Furthermore,

\footnotetext{
${ }^{3}$ Learning Spaces Toolkit, a resources for designing and sustaining technology-rich informal learning spaces. https://learningspacetoolkit.org/services-and-support/service-blueprint/
} 
blueprinting helped our staff identify and triage problems, and to set goals for implementing the many ideas for service improvements that emerged through the process.

\section{Ethics, Participation, and Privacy}

Service design offers a framework for new types and degrees of participation among different stakeholders. As a result, service design activities like service blueprinting benefit from an attunement to power dynamics, fairness, equity, and other ethical consideration of participation, including time, effort, and representation in a final co-created product or policy (Buchanan, Junginger, and Terrey 2017; Collins, Cook, and Choukeir 2017). Within the context of technology, any new technology has implications for privacy and data security, and "as an empathetic, user-centered methodology, service design offers an ethical toolset for libraries” (Drew 2018). Service blueprinting in particular can function as a complement to ethical frameworks (Sandler 2014; Ferguson, Thornley, and Gibb 2016) and privacy guidelines (ALA 2016b, 2016a) by encouraging library employees to evaluate privacy and ethics at each step of the operation. Library employees can use the blueprint to ask such questions as: When users encounter the service, what ethical questions arise? Where might user privacy be at risk? What might be the positive and negative ethical outcomes of the service, and how can library employees address these outcomes?

\section{$\underline{\text { Service Blueprinting as an Iterative Process }}$}

As demonstrated and described above in our case study, the service blueprint can be revisited and revised over time as the service itself changes and evolves. In this way, the service blueprint is more than a single snapshot in time. It can serve as a living document that reflects the growth and change of the library (Marquez and Downey 2017). We created 3 blueprints over 2 years for a single service, and each time the blueprint itself revealed the changing nature of technology, library services, library staffing, and the intertwined and ever-evolving relations among all parts in the library ecosystem.

\section{One tool among many}

The service blueprint provides one view into a service. Greater insights can be developed when the service blueprint is used in complement with other related service design tools. Journey mapping, user interviews, ecology maps, and mobile ethnographies are just a few examples of related design approaches that can complement a service blueprint (Schmidt and Etches 2014; Marquez and Downey 2016).

\section{Advocating for the Blueprint}

Just as a library service is embedded within a complex, interconnected library ecosystem, so too is the blueprint itself one part of a larger system of decision-making within a library. The blueprint-like the service it represents-does not exist in a vacuum. The longer-term 
usefulness of a blueprint relies on clear communication and buy-in with the library organization and especially the leadership team. We see two primary strategies for ensuring that the insights and ideas of blueprinting are able to find implementation. First, a member of the library's leadership team and/or those who are accountable for the service should participate in the creation of the blueprint itself. This can help establish an advocate for the blueprint, who can then carry forward the recommendations for improvement at higher levels in the organization. Second, the blueprinting team can communicate widely about the process and product of the blueprinting exercise, and help direct others to the blueprint and a summary of its recommendations.

\section{Conclusion}

The blueprint is an adaptable, useful tool for designing, assessing, and improving library services. In our case, we applied the service blueprint over three iterations to a new visualization display wall. The collaborative process of creating the blueprint generated new insights about the evolving operation of the service, and also led to real service improvements for our users. The blueprint also served as a demonstration of the interconnectedness of our staff, services, technologies, and people. Our blueprints of one service revealed the fullness and complexity of our multifaceted library ecosystem. In sum, we recommend that other libraries consider applying blueprinting and other service design methods for their own services, with a view towards assessing and improving staff and user experiences.

\section{References}

Adams Becker, S., M. Cummins, C. Giesinger Hall, V. Ananthanarayanan, K. Langley, and N. Wolfson. 2017. NMC horizon report: 2017 library edition. Austin, Texas: The New Media Consortium. http://cdn.nmc.org/media/2017-nmc-horizon-report-library-EN.pdf.

ALA. 2016a. Library privacy checklists. Intellectual Freedom Committee of the American Library Association. 2016. Accessed March 23, 2019. http://www.ala.org/advocacy/privacy/checklists.

ALA. 2016b. Library privacy guidelines. Intellectual Freedom Committee of the American Library Association. 2016. Accessed March 23, 2019. http://www.ala.org/advocacy/privacy/guidelines.

van Arnhem, J.-P., C. Elliott, and M. Rose, eds. 2018. Augmented and virtual reality in libraries. Lanham, MD: Rowman \& Littlefield. 
Bertot, J. C. 2009. Public access technologies in public libraries: effects and implications. Information Technology and Libraries 28 (2):81-91. doi:10.6017/ital.v28i2.3176.

Block, C. 2017. Managing Library Technology: A LITA guide. Lanham, MD: Rowman \& Littlefield.

Brosz, J. E., P. Rashleigh, and J. Boyer. 2015. Experiences with high resolution display walls in academic libraries. presented at the CNI Fall 2015 Membership Meeting, Washington, DC, December 14. https://www.cni.org/topics/spaces/experiences-with-high-resolutiondisplay-walls-in-academic-libraries.

Brown, J., J. T. Crocamo, A. Bielskas, W. B. Ellie Ransom, K. W. Vanti, and J. Brown. 2017. Evolving skills for emerging technologies: a collaborative approach. Library Hi Tech 35 (3):346-59. doi:10.1108/LHT-12-2016-0156.

Buchanan, C., S. Junginger, and N. Terrey. 2017. Service design in policy making. In Designing for service: key issues and new directions, ed. D. Sangiorgi and A. Prendiville, 183-98. New York: Bloomsbury.

Clark, L., and K. Palmer. 2005. "U.S. public libraries providing unprecedented access to computers, the internet, and technology training." Text. ALA News and Press Center. June 23, 2005.

http://www.ala.org/news/news/pressreleases2005/june2005/librariescomputeraccess.

Collins, K., M. R. Cook, and J. Choukeir. 2017. Designing on the spikes of injustice: representation and co-design. In Designing for service: key issues and new directions, ed. D. Sangiorgi and A. Prendiville, 106-16. New York: Bloomsbury.

Deissler, C. H., L. Ding, K. L. Neumann, and T. J. Kopcha. 2015. Professional learning networks to support school librarians' development of instructional technology expertise. TechTrends 59 (3):27-40. doi:10.1007/s11528-015-0850-1.

Deitering, A.-M., and B. Filar-Williams. 2018. Make it work: using service design to support collaboration in challenging times. International Information \& Library Review 50 (1):5459. doi:10.1080/10572317.2017.1422901.

Drew, C. 2018. Design for data ethics: using service design approaches to operationalize ethical principles on four projects. Philosophical Transactions of the Royal Society A: Mathematical, Physical and Engineering Sciences 376 (2128):20170353. doi:10.1098/rsta.2017.0353.

Ferguson, S., C. Thornley, and F. Gibb. 2015. How do libraries manage the ethical and privacy issues of RFID implementation? A qualitative investigation into the decisionmaking processes of ten libraries. Journal of Librarianship and Information Science 47 (2):117-30. doi:10.1177/0961000613518572. 
Ferguson, S., C. Thornley, and F. Gibb. 2016. Beyond codes of ethics: how library and information professionals navigate ethical dilemmas in a complex and dynamic information environment. International Journal of Information Management 36 (4):543-56. doi:10.1016/i.ijinfomgt.2016.02.012.

Ippoliti, C. 2018. The Savvy academic librarian's guide to technological innovation: moving beyond the wow factor. Lanham, MD: Rowman \& Littlefield.

Kirsch, B. A. 2018. The LITA guide to no- or low-cost technology tools for libraries. Lanham, MD: Rowman \& Littlefield.

Kritikos, K. C., and M. Zimmer. 2017. Privacy policies and practices with cloud-based services in public libraries: an exploratory case of BiblioCommons. Journal of Intellectual Freedom \& Privacy 2 (1):23-37. doi:10.5860/jifp.v2i1.6252.

Marquez, J., and A. Downey. 2015a. Service design: an introduction to a holistic assessment methodology of library services. Weave: Journal of Library User Experience 1:2. doi:10.3998/weave.12535642.0001.201.

Marquez, J., and A. Downey. 2015b. Service design: toward a holistic assessment of the library. PNLA Quarterly 80 (1):11.

Marquez, J. J., and A. Downey. 2016. Library service design: A LITA guide to holistic assessment, insight, and improvement. Lanham, Maryland: Rowman \& Littlefield.

Marquez, J. J., and A. Downey. 2017. Getting started in service design: a how-to-do-it manual. Chicago: American Library Association.

Marquez, J. J., A. Downey, and R. Clement. 2015. Walking a mile in the user's shoes: customer journey mapping as a method to understanding the user experience. Internet Reference Services Quarterly 20 (3-4):135-50. doi:10.1080/10875301.2015.1107000.

Meyer, A., and I. Fourie. 2015. What to make of makerspaces: tools and DIY only or is there an interconnected information resources space? Library Hi Tech 33 (4):519-25. doi:10.1108/LHT-09-2015-0092.

Moorefield-Lang, H. 2015. Change in the making: makerspaces and the ever-changing landscape of libraries. TechTrends 59 (3):107-12. doi:10.1007/s11528-015-0860-Z.

Nichols Hess, A., R. LaPorte-Fiori, and K. Engwall. 2015. Preserving patron privacy in the 21st century academic library. The Journal of Academic Librarianship 41 (1):105-14. doi:10.1016/i.acalib.2014.10.010.

O'Brien, P., S. W. H. Young, K. Arlitsch, and K. Benedict. 2018. Protecting privacy on the web: a study of HTTPS and google analytics implementation in academic library websites. Online Information Review 42 (6):734-51. doi:10.1108/0IR-02-2018-0056. 
Sandler, R. L. ed, Ethics and emerging technologies (London: Palgrave Macmillan UK, 2014). doi:10.1057/9781137349088 1

Schmidt, A., and A. Etches. 2014. Useful, usable, desirable: applying user experience design to your library. Chicago: American Library Association Editions.

Shostack, G. L. 1984. Designing services that deliver. Harvard Business Review. Accessed January 1, 1984. https://hbr.org/1984/01/designing-services-that-deliver.

Silveira, D. 2018. Library technology planning for today and tomorrow: A LITA guide. Lanham, MD: Rowman \& Littlefield.

Weiner, S. G. 2003. Resistance to change in libraries: application of communication theories. Portal: Libraries and the Academy 3 (1):69-78. doi:10.1353/pla.2003.0022.

Willett, R. 2016. Making, makers, and makerspaces: a discourse analysis of professional journal articles and blog posts about makerspaces in public libraries. The Library Quarterly 86 (3):313-29. doi:10.1086/686676.

Young, S. W. H., S. Mannheimer, D. Rossmann, D. Swedman, and J. D. Shanks. 2018. Assessing and improving library technology with service blueprinting. Journal of Escience Librarianship 7 (2). doi: 10.7191/jeslib.2018.1134.

Youngman, D. C. 1999. Library staffing considerations in the age of technology: basic elements for managing change. Issues in Science and Technology Librarianship. doi:10.5062/f45t3hgj. 